SHORT REPORT

\title{
Skinfold measurements at birth: sex and anthropometric influence
}

\author{
G Rodríguez, M P Samper, J L Olivares, P Ventura, L A Moreno, J M Pérez-González
}

Arch Dis Child Fetal Neonatal Ed 2005;90:F273-F275. doi: 10.1136/adc.2004.060723

Weight, length, and skinfold thicknesses were measured in 4634 term and preterm neonates. Sex and weight/length ratio were important determinants of the amount and distribution of the subcutaneous fat store at birth. Gestational age, weight, length, and other ponderal indices did not explain subcutaneous fat variability.

A ssessment of nutritional status at birth is useful for evaluating early and later neonatal outcome. ${ }^{1}$ Weight, length, and the ratios between them are the variables most often measured. Among others, the ponderal index (PI) (weight/length ${ }^{3}$ ) is used to classify small for gestational age neonates with intrauterine growth retardation, and the weight/length ratio (W/L) to assess neonatal thinness/ fatness. ${ }^{2-4}$

Measurement of skinfold thickness (ST) is a fast and noninvasive method that may also help us to explore infant nutritional status. ST has shown good correlation with total body fat mass in newborns. ${ }^{5}$ Recently, it has been reported that term and preterm female newborns had a more centralised pattern and more subcutaneous fat than male newborns measured by ST. ${ }^{6}$ The aims of this study were both to analyse whether anthropometry, sex, or gestational age determine the variability in subcutaneous fat store at birth, and to construct sex specific standards for ST measurements.

\section{PATIENTS AND METHODS \\ Population}

Data were obtained from 4634 neonates (2445 male and 2189 female), born in the University Clinical Hospital "Lozano Blesa", Zaragoza, Spain. The sample of term infants (37-41 gestational weeks) comprised all singleton neonates born between January 2000 and December 2002. To obtain an adequate sample size of preterms (32-36 gestational weeks), we collected data from all singletons born between January 1993 and December 2002. Gestational age was expressed in complete weeks from the last menstrual period. Infants of minority ethnic groups were not considered. We also excluded newborns with major congenital chromosomal or metabolic abnormalities, gestational diabetes, or other alterations that could affect body composition.

\section{Anthropometric measurements}

Weight $(\mathrm{g})$ was measured just after birth. Skinfolds (mm) and length $(\mathrm{cm})$ were obtained within the first 24 hours of life by the same person. Left STs were measured at four sites with Holtain skinfold callipers: triceps (TS), biceps (BS), subscapular (SBS), and suprailiac (SPS). Reliability for skinfolds was $95 \%$.

Various indexes were calculated: the sum of the four skinfolds $(\mathrm{mm})(\Sigma \mathrm{ST})=\mathrm{TS}+\mathrm{BS}+\mathrm{SPS}+\mathrm{SBS}$; central to total skinfold ratio $(\mathrm{CTS})=((\mathrm{SPS}+\mathrm{SBS}) / \Sigma \mathrm{ST}) \times 100 ; \mathrm{W} / \mathrm{L}$ $(\mathrm{kg} / \mathrm{m})$; body mass index (BMI; weight/length $\left.{ }^{2} ; \mathrm{kg} / \mathrm{m}^{2}\right)$; PI $\left(\mathrm{kg} / \mathrm{m}^{3} \times 10^{-1}\right)$.
Table 1 Number, weight, and length of neonates 3241 weeks gestation

\begin{tabular}{|c|c|c|c|}
\hline $\begin{array}{l}\text { Gestational } \\
\text { age (weeks) }\end{array}$ & $\begin{array}{l}\text { Number } \\
(\mathrm{N}=4634)\end{array}$ & Weight (g) & Length (cm) \\
\hline Boys & 2445 & & \\
\hline $32-33$ & 47 & 1805 (347) & $42.72(2.38)$ \\
\hline 34 & 53 & 2149 (344) & $44.68(2.64)$ \\
\hline 35 & 57 & $2339(365)$ & $45.50(2.23)$ \\
\hline 36 & 133 & $2595(448)$ & $47.03(2.24)$ \\
\hline 37 & 136 & 3006 (465) & $48.77(2.11)$ \\
\hline 38 & 369 & $3175(419)$ & $49.68(1.88)$ \\
\hline 39 & 772 & $3305(386)$ & $50.19(1.78)$ \\
\hline 40 & 600 & 3415 (399) & $50.72(1.58)$ \\
\hline 41 & 278 & 3563 (404) & $51.43(1.75)$ \\
\hline Girls & 2189 & & \\
\hline $32-33$ & 27 & $1837(458)$ & $42.64(2.33)$ \\
\hline 34 & 53 & 2113 (349) & $44.27(2.17)$ \\
\hline 35 & 52 & 2276 (348) & 45.48 (1.91) \\
\hline 36 & 101 & $2515(402)$ & $46.60(2.34)$ \\
\hline 37 & 126 & 2778 (389) & $47.53(1.85)$ \\
\hline 38 & 350 & 3047 (384) & $48.76(1.70)$ \\
\hline 39 & 729 & 3196 (375) & 49.56 (1.72) \\
\hline 40 & 500 & 3326 (374) & $50.09(1.70)$ \\
\hline 41 & 251 & 3390 (358) & $50.35(1.47)$ \\
\hline
\end{tabular}

\section{Statistical analysis}

Stepwise regression analyses were performed with $\Sigma$ ST and CTS as dependent variables, and sex, gestational age, weight, length, W/L, BMI, and PI as independent variables.

Smoothed centile curves for anthropometric variables were constructed by sex and gestational age groups according to the LMS method for growth standards, using the LMS program version 1.16 from the Institute of Child Health (London, UK). ${ }^{7}$ This method monitors the changing skewness of the distribution during growth by calculating the Box-Cox power needed to transform the data to normality at each age, and displaying the results as a smooth curve of power plotted against age.

\section{RESULTS}

Table 1 shows weight and length at birth. Tables 2 and 3 (which can be found at http://www.archdischild.com/ supplemental) detail the results of stepwise regression analyses. In the entire group, W/L explained $39.7 \%$ of the $\Sigma$ ST variability, and sex added $1.7 \%$ to it. Sex also explained $2 \%$ of CTS variability, and W/L added $0.5 \%$ to it. Divided on sex groups, the two sexes showed similar results. W/L predicted $40.1 \%$ and $41.9 \%$ of $\Sigma S T$ in female and male neonates respectively. No significant contribution of gestational age, weight, length, BMI, or PI was found for $\Sigma$ ST or CTS in either male or female newborns.

Abbreviations: $\mathrm{BMI}$, body mass index; CTS, central to total skinfold ratio; Pl, ponderal index; ST, skinfold thickness; W/L, weight/length ratio 
Table 4 Smoothed centiles for the sum of four skinfolds $(\mathrm{mm})$ and gestational age in newborns

\begin{tabular}{|c|c|c|c|c|c|c|c|c|}
\hline \multirow{2}{*}{$\begin{array}{l}\text { Gestational age } \\
\text { (weeks) }\end{array}$} & \multirow[b]{2}{*}{ Mean (SD) } & \multicolumn{7}{|c|}{ Centile } \\
\hline & & 3 rd & 10th & 25th & 50th & 75th & 90th & 97th \\
\hline \multicolumn{9}{|l|}{ Boys } \\
\hline 33 & $8.96(1.93)$ & 5.5 & 6.7 & 8.1 & 9.6 & 11.3 & 12.8 & 14.4 \\
\hline 34 & $10.61(2.51)$ & 6.0 & 7.3 & 8.7 & 10.4 & 12.1 & 13.7 & 15.4 \\
\hline 35 & $11.20(2.06)$ & 6.6 & 8.0 & 9.4 & 11.2 & 13.0 & 14.6 & 16.4 \\
\hline 36 & $12.01(2.80)$ & 7.5 & 8.9 & 10.5 & 12.3 & 14.2 & 16.0 & 17.9 \\
\hline 37 & $14.45(3.38)$ & 8.5 & 10.0 & 11.6 & 13.6 & 15.6 & 17.5 & 19.5 \\
\hline 38 & $14.33(2.86)$ & 9.2 & 10.8 & 12.4 & 14.3 & 16.3 & 18.3 & 20.3 \\
\hline 39 & 15.08 (2.89) & 9.8 & 11.3 & 12.9 & 14.8 & 16.8 & 18.7 & 20.6 \\
\hline 40 & $15.17(2.77)$ & 10.2 & 11.7 & 13.2 & 15.0 & 17.0 & 18.8 & 20.7 \\
\hline 41 & $15.33(2.74)$ & 10.4 & 11.9 & 13.4 & 15.2 & 17.1 & 18.8 & 20.6 \\
\hline \multicolumn{9}{|l|}{ Girls } \\
\hline 33 & 9.91 (2.39) & 5.6 & 6.8 & 8.2 & 9.9 & 11.7 & 13.4 & 15.2 \\
\hline 34 & $11.23(3.02)$ & 6.1 & 7.5 & 8.9 & 10.7 & 12.5 & 14.3 & 16.1 \\
\hline 35 & $11.38(2.34)$ & 6.7 & 8.1 & 9.6 & 11.4 & 13.3 & 15.1 & 16.9 \\
\hline 36 & $12.31(3.22)$ & 7.6 & 9.1 & 10.7 & 12.6 & 14.5 & 16.3 & 18.2 \\
\hline 37 & $13.99(2.89)$ & 8.7 & 10.2 & 11.9 & 13.9 & 15.9 & 17.8 & 19.8 \\
\hline 38 & $15.18(3.07)$ & 9.6 & 11.2 & 12.9 & 14.9 & 17.0 & 18.9 & 20.9 \\
\hline 39 & $15.37(2.77)$ & 10.3 & 11.8 & 13.4 & 15.3 & 17.3 & 19.3 & 21.3 \\
\hline 40 & $15.58(2.91)$ & 10.7 & 12.1 & 13.7 & 15.5 & 17.5 & 19.5 & 21.5 \\
\hline 41 & 16.18 (2.99) & 11.2 & 12.6 & 14.1 & 15.9 & 17.9 & 19.9 & 22.0 \\
\hline
\end{tabular}

Figures 1 and 2 (which can be found at http://www. archdischild.com/supplemental) and tables 4 and 5 show smoothed centiles for $\Sigma$ ST and the CTS ratio by sex and gestational age groups.

\section{DISCUSSION}

ST measurements of subcutaneous fat may provide information about perinatal nutritional status and neonatal outcome. ${ }^{8}$ In a study performed by magnetic resonance imaging, total and subcutaneous fat mass were lower in small for gestational age neonates than in those of appropriate size for gestational age, but there were no differences in intraabdominal fat mass. ${ }^{9}$ These results suggest that subcutaneous and intra-abdominal adipose tissue compartments are under different regulatory control during intrauterine life. Subcutaneous adipose tissue reduction at birth seems to be related to intrauterine growth restriction.
Body weight is the best independent predictor of body composition in preterm and term infants, accounting for $84 \%$ of the variation in fat mass; sex and length are additional determinants. ${ }^{10}{ }^{11}$ In our study, W/L and sex were the most powerful predictors of $\Sigma$ ST. Other anthropometric variables or ratios considered in the stepwise regression (gestational age, weight, length, BMI, PI, or CTS) did not explain subcutaneous fat variability at birth.

Body fat increases throughout gestation in both sexes, and female infants have higher body fat percentage than male infants. ${ }^{6}{ }^{10-12}$ However, there are limited data about neonatal distribution of subcutaneous body fat. In a recent study reported by our group, CTS did not vary significantly from 32 to 41 weeks, but girls had a more centralised pattern of subcutaneous fat than boys. ${ }^{6}$

In conclusion, W/L and sex are both important determinants of neonatal subcutaneous fat, and sex also influences its distribution. Body weight by itself, length, BMI, PI, and

Table 5 Smoothed centiles for the total to central skinfolds ratio (\%) and gestational age in newborns

\begin{tabular}{rllllllll}
\hline $\begin{array}{l}\text { Gestational } \\
\text { age (weeks) }\end{array}$ & Mean (SD) & Centile & & & & \\
\cline { 4 - 8 } & & & & & & \\
3rd & 10th & 25th & 50th & 75th & 90th & 97th \\
\hline Boys & & & & & & & & \\
33 & $47.24(3.93)$ & 40.9 & 43.0 & 45.1 & 47.5 & 50.0 & 52.2 & 54.4 \\
34 & $47.87(3.73)$ & 41.1 & 43.2 & 45.3 & 47.7 & 50.0 & 52.1 & 54.2 \\
35 & $47.55(3.18)$ & 41.4 & 43.5 & 45.6 & 47.9 & 50.1 & 52.1 & 54.0 \\
36 & $48.28(3.24)$ & 41.6 & 43.7 & 45.7 & 48.0 & 50.1 & 52.1 & 53.9 \\
37 & $47.87(3.01)$ & 41.6 & 43.7 & 45.7 & 47.8 & 50.0 & 51.8 & 53.7 \\
38 & $47.64(3.12)$ & 41.7 & 43.7 & 45.7 & 47.8 & 49.9 & 51.8 & 53.6 \\
39 & $48.04(3.25)$ & 42.0 & 43.9 & 45.9 & 48.0 & 50.1 & 52.0 & 53.8 \\
40 & $48.17(3.06)$ & 42.1 & 44.1 & 46.0 & 48.2 & 50.3 & 52.1 & 53.9 \\
41 & $48.13(3.19)$ & 42.1 & 44.1 & 46.0 & 48.2 & 50.3 & 52.1 & 53.9 \\
Girls & & & & & & & & \\
33 & $48.70(4.14)$ & 41.8 & 44.3 & 46.7 & 49.1 & 51.5 & 53.5 & 55.4 \\
34 & $48.80(4.16)$ & 42.4 & 44.6 & 46.8 & 49.2 & 51.5 & 53.4 & 55.3 \\
35 & $49.17(3.02)$ & 42.9 & 45.0 & 47.0 & 49.2 & 51.4 & 53.3 & 55.2 \\
36 & $49.03(3.08)$ & 43.2 & 45.1 & 471 & 49.3 & 51.4 & 53.3 & 55.1 \\
37 & $49.48(3.05)$ & 43.1 & 45.0 & 47.0 & 49.1 & 51.2 & 53.1 & 55.0 \\
38 & $48.71(3.09)$ & 42.8 & 44.7 & 46.6 & 48.7 & 50.9 & 52.8 & 54.8 \\
39 & $48.76(3.30)$ & 42.6 & 44.5 & 46.5 & 48.7 & 50.9 & 53.0 & 55.0 \\
40 & $49.15(3.47)$ & 42.6 & 44.6 & 46.7 & 48.9 & 51.3 & 53.4 & 55.5 \\
41 & $49.06(3.52)$ & 42.6 & 44.6 & 46.7 & 49.0 & 51.5 & 53.7 & 55.9 \\
\hline & & & & & & & & \\
\hline
\end{tabular}


gestational age do not determine the subcutaneous fat variability at birth. Neonatal fat store and its distribution may reflect perinatal nutritional status. Therefore more studies are required to relate fat mass measurements at birth to intrauterine growth, early infant outcome, and later development of metabolic alterations and diseases. For this purpose, we have constructed sex specific standards for $\Sigma$ ST and CTS to be used in future studies.

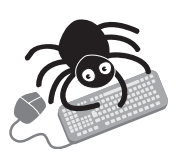

All the figures and tables 2 and 3 can be found at http://www.archdischild.com/supplemental.

\section{Authors' affiliations}

G Rodríguez, M P Samper, J L Olivares, P Ventura, J M PérezGonzález, Departamento de Pediatría, Radiología y Medicina Física, University of Zaragoza, Zaragoza, Spain

L A Moreno, EU de Ciencias de la Salud, University of Zaragoza

Competing interests: none declared

Correspondence to: Professor Rodríguez, Departamento de Pediatría, Radiología y Medicina Física, Facultad de Medicina, Universidad de Zaragoza, C/Domingo Miral s/n, 50009 Zaragoza, Spain; gereva@ comz.org

Accepted 16 December 2004

\section{REFERENCES}

1 Wilcox AJ, Russell IT. Birthweight and perinatal mortality. II. On weightspecific mortality. Int J Epidemiol 1983;12:319-25.

2 Wilcox AJ. Intrauterine growth retardation: beyond birth weight criteria. Early Hum Dev 1983;8:189-93.

3 Patterson RM, Pouliot MR. Neonatal morphometrics and perinatal outcome: who is growth retarded? Am J Obstet Gynecol 1989;161:1089-90.

4 de Bruin NC, van Velthoven KA, Stijnen T, et al. Body fat and fat-free mass in infants: new and classic anthropometric indexes and prediction equations compared with total-body electrical conductivity. Am J Clin Nutr 1995;61:1195-205

5 Schmelzle HR, Fusch C. Body fat in neonates and young infants: validation of skinfold thickness versus dual-energy X-ray absorptiometry. Am J Clin Nutr 2002;76:1096-100.

6 Rodríguez G, Samper MP, Ventura P, et al. Gender differences in newborn subcutaneous fat distribution. Eur J Pediatr 2004;163:457-61.

7 Cole TJ. The LMS method for constructing normalized growth standards. Eur J Clin Nutr 1990;44:45-60.

8 Singhal A, Fewtrell M, Cole TJ, et al. Low nutrient intake and early growth for later insulin resistance in adolescents born preterm. Lancet 2003;361:1089-97.

9 Harrington TAM, Thomas EL, Frost G, et al. Distribution of adipose tissue in the newborn. Pediatr Res 2004;55:437-41.

10 Koo WWK, Walters JC, Hockman EM. Body composition in human infants at birth and postnatally. J Nutr 2000;130:2188-94.

11 Rigo J, Nyamugabo K, Picaud JC, et al. Reference values of body composition obtained by dual energy $X$-ray absorptiometry in preterm and term neonates. J Pediatr Gastroenterol Nutr 1998;27:184-90.

12 Guihard-Costa AM, Grangé G, Larroche JC, et al. Sexual differences in anthropometric measurements in French newborns. Biol Neonate 1997;72:156-64. 